\title{
DELIRIO DE ANTÍGONA ELEMENTOS PARA UNA PEDAGOGÍA FEMINISTA DECOLONIAL*
}

\author{
HELENA LÓPEZ GONZÁLEZ DE ORDUÑA**
}

Recibido: 1 de noviembre de 2017 - Aceptado: 25 de noviembre de 2017 DOI: $10.24142 /$ raju.v12n25a9

\section{Resumen}

Este artículo pretende examinar cómo un feminismo decolonial, situado en Latinoamérica, puede movilizar una crítica muy potente al capitalismo heteronormativo global. Además, y con atención a ejemplos de la práctica docente en México, se propone una consideración de esta crítica desde el punto de vista de su pedagogía en la educación superior. Con este fin consideramos las nociones teóricas de experiencia y memoria.

Palabras clave: feminismo decolonial, pedagogía, experiencia, memoria.

* Este artículo es una versión de la ponencia presentada el 17 de julio de 2014 en la Universidad de San Buenaventura, Medellín, en el marco del Primer Encuentro sobre Pedagogía, Memoria y Género.

** Investigadora en el Centro de Investigaciones y Estudios de Género (CIEG) de la Universidad Nacional Autónoma de México (UNAM). Correo electrónico: hlgo@ hotmail.com 


\title{
DELIRIUM OF ANTIGONE ELEMENTS FOR A DECOLONIAL FEMINIST PEDAGOGY
}

\begin{abstract}
This article aims to examine how a decolonial feminism located in Latin America can mobilize a very powerful critique of global heteronormative capitalism. In addition, and with attention to examples of my own teaching practice in Mexico, I propose a consideration of this criticism from the point of view of its pedagogy in higher education. To this end I consider the theoretical notions of experience and memory.
\end{abstract}

Keywords: decolonial feminism, pedagogy, experience, memory. 


\section{INTRODUCCIÓN}

A lo largo de este artículo se comparten algunas ideas sobre la producción y socialización de un tipo particular de conocimiento emancipador. Las razones para comprometerse con proyectos emancipatorios - en el aula y otros espacios sociales - son numerosas y variadas. Ahora, esta abundancia de problemas, en principio distantes entre sí, como verter residuos tóxicos en un río y asesinar serial e impunemente mujeres y hombres jóvenes pobres y racializados en México, pertenece a un mismo orden material y cultural denominado capitalismo heteronormativo.

Para examinar una pedagogía feminista decolonial, que nos permita pensar críticamente y actuar de manera transformativa respecto de un orden social que, nos parece no solamente injusto, sino también disfuncional, destructivo y no sustentable, se ha organizado este artículo en tres partes: primero se plantea una definición operativa de lo que se llama capitalismo heteronormativo y su relación con el feminismo; luego se justifica el por qué parece que el cruce entre feminismo y decolonialidad constituye una modalidad muy potente dentro de lo que se llama las pedagogías críticas y, por último, se "aterrizan" varios aspectos teóricos que luego se exponen a partir de ejemplos educativos concretos, en los que, como se verá más adelante, nociones como justicia cognitiva, memoria y experiencia juegan un papel muy importante.

\section{CAPITALISMO HETERONORMATIVO Y FEMINISMO}

El marxismo ortodoxo entiende la relación entre estructura económica y superestructura ideológica de una manera determinista: los modos y relaciones de producción le dan forma a los valores de la cultura capitalista, de manera que estos podrían considerarse el reflejo mecánico de la economía. Ahora, ¿estamos convencidos de que este modelo da cuenta del perfecto funcionamiento del capital? Es decir, ¿puede este modelo explicar el consentimiento, no por coerción, es decir el natural y general consentimiento, en un sistema económico basado en la acumulación de plusvalía que garantiza una abusiva división internacional del trabajo generadora de profundas desigualdades sociales y devastación medioambiental? Esta es en realidad la pregunta que se hace Gramsci y que inaugura un marxismo heterodoxo y más culturalista, para el que la superestructura es un polisis- 
tema semiautónomo y el capitalismo un sistema de producción económica; apropiándonos del vocabulario del capitalismo, como un estilo de vida. ¿Y en qué consiste la robustez de este estilo de vida? La respuesta corta sería que la cultura capitalista se reproduce con gran eficiencia gracias a su extraordinaria capacidad para generar deseos (y esto, aunque vayan en contra de nuestros propios intereses) que son funcionales a la lógica del capital. En este sentido, no existirían tantas diferencias entre la familia burguesa del siglo XIX y la familia de lesbianas profesionistas que retrata la reciente película estadounidense dirigida por Lisa Cholodenko Los niños están bien (2010). Esto es posible porque ambos arreglos sociales, en principio tan diferentes, responden a las necesidades de lo que Lauren Berlant y Michael Warner llaman heteronormatividad, que reformula con un giro desencializante el concepto de heterosexualidad obligatoria como institución política, que hay que recordar le debemos al feminismo lésbico (Rich, 1980). Lo importante es que la heteronormatividad se plantea más allá de la opción sexual (entre sujetos del mismo sexo o de sexo diferente) como la ideología total del capitalismo:

Este sentido de lo apropiado -incorporado a todas las cosas y no sólo al sexo- es lo que llamamos heteronormatividad. La heteronormatividad es más que una ideología, o prejuicio o fobia contra gays y lesbianas; se produce en casi todos los aspectos de las formas y arreglos sociales: la nacionalidad, el estado y la ley; el comercio; la medicina; la educación; así como en las convenciones y afectos de las narrativas románticas y otros espacios protegidos de la cultura (Berlant y Warner, 2000, p. 318) (traducción de la autora).

El feminismo, entendido como un movimiento social y una teoría, pone a nuestra disposición una crítica al capitalismo heteronormativo. En realidad, la situación es mucho más complicada. Pero digamos, para simplificar, que un determinado tipo de feminismo — que desde luego nada tiene que ver con otras versiones del feminismo como las que históricamente han buscado la igualdad de derechos políticos y civiles con los hombres sin cuestionar la estructura del Estado- está interesado en avanzar una crítica radical al capitalismo heteronormativo. $\mathrm{Y}$ es precisamente por la voluntad antisistémica de este feminismo, opuesto al anhelo de asimilación de otros feminismos, que se habla del delirio de Antígona.

Antígona, hija de Edipo y Yocasta, entierra en Tebas a su hermano Polinices a pesar de que Creonte había prohibido su sepultura en el recinto 
de la ciudad. Al desobedecer, Antígona es condenada a ser enterrada viva. Para evitar esta tortura se suicida ahorcándose. ¿Por qué la fuerza de este mito reverbera en el impulso de un feminismo anticapitalista y antiheteronormativo? El delirio ${ }^{1}$ de Antígona ha fascinado desde hace siglos a muchos pensadores y escritores: Luce Irigaray, María Zambrano, Georg Wilhelm Friedrich Hegel, Jacques Lacan, Bertolt Brecht o Jean Anouilh, por citar solo algunos de los nombres que se han interesado por la extraordinaria fantasía política que moviliza Antígona. ${ }^{2}$ Para nuestros propósitos, de identificación de un feminismo antisistema, citaremos el final de un texto bellísimo de Judith Butler (2001), una de las pensadoras más estimulantes del feminismo metropolitano de la Tercera Ola:

¿Quién es Antígona dentro de esta escena y qué vamos a hacer con sus palabras, convertidas en acontecimientos dramáticos, actos realizativos? Ella no pertenece a lo humano, pero habla su lenguaje. Actúa, aunque se le ha prohibido la acción, y su acto apenas es una simple asimilación de una norma existente. Y cuando actúa, como quien no tiene derecho a actuar, altera el vocabulario del parentesco que es precondición de lo humano, e implícitamente se plantea la cuestión de cuáles deben ser en realidad esas precondiciones. Antígona habla desde el lenguaje del derecho del que está excluida, participando en el lenguaje de la reivindicación con el cual no es posible ningún tipo de identificación final. Si ella es humana, entonces lo humano ha entrado en catacresis: ya no conocemos su uso correcto. $Y$ en la medida que ocupa el lenguaje que nunca puede pertenecerle, ella funciona como un quiasmo dentro del vocabulario de las normas políticas. Si el parentesco es la precondición de lo humano, entonces Antígona es la ocasión para un nuevo campo de lo humano, logrado a través de catacresis política, la que se da cuando el menos que humano habla como humano, cuando el género es desplazado, y el parentesco se hunde en sus propias leyes fundadoras. Ella actúa, habla, se convierte en alguien para quien el acto de habla es un crimen fatal, pero esta fatalidad excede su vida y entra en el discurso de la inteligibilidad como su misma prometedora fatalidad, la forma social de un futuro aberrante sin precedentes (p. 110).

1 Etimológicamente delirio contiene la partícula $d e$ —separación — y el lexema lirio — surco—. Separación del surco. El delirio es un extravío respecto de lo recto, de la norma.

2 Para una excelente historia cultural del mito de Antígona véase Steiner (2009). 


\section{FEMINISMO DECOLONIAL}

Nos interesa subrayar, de la cita anterior, que esta palabra-acto, de un feminismo, que como Antígona se sitúa en desobediencia fuera de la ley, tiene lugar. Literalmente, se dice y se hace en un lugar. Y ya que lo prometemos en el título de este artículo, que es una reflexión desde la pedagogía, diremos que este feminismo se despliega en escenarios latinoamericanos de educación superior. Hablamos desde la experiencia en México, y podría hacerse desde las experiencias en Colombia y otros países del continente americano. Si tanto la tradición de la pedagogía crítica (inspirada en las premisas de la educación popular de Paulo Freire) como la pedagogía feminista (en deuda a su vez con Freire e impulsada por el feminismo negro y lésbico de autoras como bell hooks) asignan una importancia crucial a los contextos de aprendizaje (Freire, 2009, p. 82) y a criterios de adaptabilidad situacional que toman en consideración las condiciones locales donde los sujetos construyen saberes (Castellano, 2004, pp. 83-86). Es decir, si en efecto nuestra ubicación importa, entonces confesamos que la única pedagogía feminista que nos interesa, desde esta parte del mundo, es aquella que además de buscar la crítica transformativa de las asimetrías que genera el sistema de sexo-género dominante en el tardocapitalismo asume también un compromiso decolonial.

El orden de internacionalización que se inaugura en 1492 establece una geopolítica económica, cultural, social y epistemológica basada en la colonialidad del poder (Quijano, 2000). Es decir, basada en relaciones de dominación racializada y generizada que persisten hasta hoy. El término decolonialidad, frente al de poscolonialidad, quiere enfatizar, precisamente, la persistencia de la sistemática explotación de territorios y poblaciones en las periferias de los centros de poder global que, desde luego, ha sobrevivido al fin de las administraciones coloniales y la formación de los estados-nación latinoamericanos en el siglo XIX. En realidad, los índices de violencia y pauperización en muchas regiones de Latinoamérica son en el siglo XXI incluso más aterradores que en el pasado. Veamos cómo Santiago Castro-Gómez y Ramón Grosfoguel (2007) plantean los retos de esta perspectiva:

El análisis de los procesos del sistema-mundo se hace tomando en cuenta los conocimientos sometidos/subalternizados por la visión eurocéntrica del mundo, es decir, el conocimiento práctico de los trabajadores, las mujeres, los sujetos racializados/coloniales, los gays y los 
movimientos anti-sistémicos. Esto quiere decir que aunque se tome el sistema-mundo como unidad de análisis, reconocemos también la necesidad de una corpo-política del conocimiento sin pretensión de neutralidad y objetividad (p. 21).

Trabajadores, mujeres, sujetos racializados/coloniales, gays (Castro-Gómez y Grosfoguel se olvidaron de las lesbianas), movimientos anti-sistémicos. En efecto, todos ellos oprimidos por un mismo sistema capitalista heteronormativo pero, precisamente, porque la ubicación cuenta es difícil ensayar una pedagogía crítica totalizadora cuyo sujeto subalterno contenga a todos los sujetos que mencionan Castro-Gómez y Grosfoguel. La necesidad de atender a la intersección de diferencias en nuestra corpo-política del conocimiento ha dado lugar, muy recientemente en realidad, a la articulación de un feminismo decolonial latinoamericano que reúne a académicas radicadas en Latinoamérica y en Estados Unidos (Bidaseca y Vázquez, 2011; Espinosa, Gómez y Ochoa, 2014; Gargallo, 2012; Lugones, 2008 y Mendoza, 2010). ${ }^{3}$

En relación con los objetivos de una pedagogía feminista decolonial sostiene la antropóloga mexicana Aída Hernández (2014):

...una ecología de saberes feministas no desecharía todos los conocimientos acumulados por el feminismo occidental, sino que trataría de relativizar su capacidad heurística, contextualizando sus orígenes y su espacio de enunciación, a la vez que desestabilizaría su relación jerárquica con los conocimientos emancipatorios de las mujeres indígenas, musulmanas, campesinas (p. 207).

Estamos de acuerdo con Aída Hernández, quizás salvo en la consideración, un tanto romántica, de que los únicos conocimientos emancipatorios sean los que provienen de mujeres indígenas y campesinas; hay una abundante población de mujeres urbanas, indígenas o mestizas, que también generan conocimientos locales y empoderantes como veremos a continuación. Siguiendo a Aída Hernández, una pedagogía decolonial feminista haría básicamente tres cosas para evitar un eurocentrismo epistémico universalizante. Uno, entender que la epistemología metropolitana es válida para explicar algunas cosas, pero no todas. Dos, atender a los conocimientos subyugados

3 La autora es consciente de que escritoras como Francesca Gargallo reivindican su filiación como feministas autónomas, y cuestionan la necesidad de acuñar el término de feminismo decolonial. 
de las mujeres en contextos locales. Tres, comprometerse con los dos objetivos anteriores con el propósito de promover formas de justicia cognitiva (Santos, 2009).

Ahora, estos objetivos no son nada fáciles. Y esto porque la mayoría de los que nos dedicamos a la educación superior provenimos de una clase media formada en inercias de producción y transmisión de conocimiento euro-anglo-céntricas (y, desde luego, nada feministas). Por muy buenas intenciones que tengamos es difícil — decimos difícil, no imposible- deshacernos de nuestro habitus intelectual. Pero igual lo intentamos a partir de dos nociones importantes para el feminismo decolonial: experiencia y memoria. Nos referiremos a cada una de ellas con algunos ejemplos extraídos de los ámbitos pedagógicos con los que hace varios años estamos familiarizados algunos docentes en México.

\section{LA DIMENSIÓN PEDAGÓGICA}

Experiencia es un concepto fundacional del feminismo, por alguna misteriosa razón un tanto devaluado en los años ochenta y noventa del siglo pasado por el pensamiento postestructuralista anglosajón, ${ }^{4}$ y de nuevo reivindicado por el feminismo decolonial desde Latinoamérica: "[La descolonización] crea una especie de 'cimarronaje' intelectual, de prácticas sociales y la construcción de pensamiento propio de acuerdo a experiencias concretas" (Curiel, 2014, p. 326) (la cursiva es de la autora). No se trata de creer que la experiencia de una mujer sea buena y verdadera. Sin duda esa experiencia es el efecto, como la experiencia de cualquiera (hombre o mujer), de discursos buenos y malos, verdaderos y falsos. Se trata, más bien, de atender a la operatividad de esa experiencia, a sus condiciones de efectividad y preguntarse para qué sirve.

Entre los años 2011 y 2013 se participó en un proyecto de investigación-acción del PUEG-UNAM en una cárcel de mujeres de México DF. Les cuento que siendo atea y sin hijos pero escuchando durante horas los relatos de muchas internas he entendido cómo la religión y distintas formas de es-

4 La discusión en el contexto anglosajón está determinada por el influyente artículo de Joan Scott, publicado en 1991, "Experiencia" (2001) y encuentra en Linda Martín Alcoff (2000) a una de sus más convincentes críticas. En este mismo contexto, el interés, en el nuevo milenio, de muchas feministas por la dimensión afectiva de la vida subjetiva y social ha supuesto una renovada fenomenología del cuerpo que recupera los aspectos experienciales. 
piritualidad, así como la maternidad, pueden ser prácticas significantes que habilitan condiciones de agencia, es decir, condiciones que permiten a estas mujeres tener mayor control sobre sus vidas.

Un segundo ejemplo servirá para mostrar, brevemente, cómo la noción de experiencia puede movilizar pedagogías de la alteridad que eviten reducir a los sujetos del feminismo a un simple reflejo de nosotras mismas, a partir de teorías que a menudo no son capaces de aprehender experiencias subalternas. ${ }^{5} \mathrm{Y}$ esto, porque desde un principio estas experiencias han estado excluidas de los dispositivos dominantes de interpretación. En este sentido, la antropóloga Emma Chirix ha estudiado cómo la experiencia histórica de las comadronas, entre mujeres kaqchikeles, de Guatemala es una práctica de cuidado con elementos, diferentes a los de la medicina y la ginecología occidentales, muy valorados y de uso efectivo en estas comunidades. Una deconstrucción feminista del discurso científico hegemónico deberá, por lo tanto, suspender las premisas de su propio paradigma para adoptar otros puntos de vista informados por lógicas distintas a las de la ciencia "autorizada".

Consideremos este tercer ejemplo. Las colectivas feministas en México recurren a estrategias no institucionales - como el escrache, las marchas, el artivismo, la denuncia en redes sociales y medios de comunicación-para llevar a cabo formas de intervención parajudicial. ${ }^{6}$ Una crítica frecuente acusa a estas colectivas feministas de no dejar que la justicia haga su trabajo; pero, en un país como México, con un sistema de justicia $100 \%$ ineficiente, en el contexto de lo que se denomina un Estado fallido, ¿tiene sentido apelar a la ideología metropolitana de la ciudadanía?

Sobre el concepto de memoria hay que señalar que la transmisión intergeneracional de conocimiento es uno de los elementos nodales de la pedagogía decolonial feminista. Al respecto, afirma la antropóloga colombiana Diana Gómez (2013):

5 Sobre este carácter especular del conocimiento — un rasgo históricamente persistente en la epistemología eurocéntrica - y las posibilidades de sortear este riesgo véase la formulación imaginativa de la escritora mexicana Cristina Rivera Garza, en su hermoso relato breve "Autoetnografía con otro" (2008).

6 Entre otras podemos citar el trabajo de la colectiva "Ali somos todas", surgida a raíz del asesinato en 2009 de la estudiante de la Universidad Autónoma de México (UNAM) Alí Dessiré Cuevas Castrejón. O la plataforma creada para defender la inocencia de la joven Yakiri Rubio, acusada de homicidio al defenderse contra uno de los dos agresores que, en diciembre de 2013, en la colonia Doctores de la Ciudad de México, la secuestraron, violaron e intentaron matar. 
Cuando introduje en el texto referencias a la educación popular (del brasileño Paulo Freire) y a la investigación participativa (del colombiano Orlando Fals Borda), así como los acumulados de otros movimientos, estaba pensando en que una pedagogía feminista descolonial se nutre de esas experiencias pasadas de Abya Yala. Es decir, una pedagogía feminista descolonial si bien está aportando elementos nuevos, recoge un camino andado por movimientos como el feminismo, el indígena, el afro, entre muchos otros (pp. 427-428).

Si regresamos a los tres ejemplos anteriores - en los que la atención a distintas experiencias de mujeres puede ser utilizada en el aula para tomarse muy en serio saberes poco importantes, o incluso indeseables de acuerdo con los modelos de conocimiento dominantes - es evidente que la noción de memoria está presente en al menos dos sentidos. ${ }^{7}$ Por un lado, y como vimos en los casos de las mujeres en reclusión y el de las comadronas kaqchikeles, se trata de una recuperación activa de conocimientos invisibilizados por la política epistemológica prevalente en nuestras universidades. Y, por otro, nuestro trabajo de memoria consiste también en una ética resistente en zonas de abandono olvidadas por las instituciones del Estado. El ejemplo de la intervención en una cárcel de mujeres, a partir de un proyecto de investigación-acción, o los dos de trabajo colectivo desde el activismo feminista, demuestran cómo la obstinación del recuerdo social puede cumplir un papel fundamental allí donde el Estado no tiene la voluntad de garantizar derechos fundamentales (el acceso a la educación o a la justicia) a millones de personas nacidas en territorio mexicano.

En conclusión, hemos visto cómo los desafíos que plantea una pedagogía feminista decolonial demuestran las complicaciones imbricadas en términos epistemológicos, educativos, éticos y políticos: “...la injusticia social descansa en la injusticia cognitiva” (Santos, 2009, pp. 114-115). Son,

7 Los Estudios de la Memoria se configuran en el campo académico internacional en la década del ochenta del siglo pasado, por la confluencia de diferentes factores: impacto del pensamiento posestructuralista en los regímenes hegemónicos de producción de verdad (notablemente en la Historia como disciplina), impacto de la historia social, crisis de las ideologías modernas del progreso, memoria del Holocausto (en los contextos académicos alemán y anglosajón), procesos de justicia transicional (Latinoamérica, España, Sudáfrica, etc.), influencia de la educación popular y la investigación-acción participativa (Latinoamérica). La agenda teórica del campo tiene una vocación inicial progresista, con metodologías de abajo-a-arriba, que ha sido muy atractiva para la investigación feminista (Cuevas, 2013 y Radstone y Hodgkin, 2003). 
por lo tanto, retos complejos, pero también muy prometedores. Por eso decimos en el título de este artículo que se parecen a Antígona delirando.

\section{REFERENCIAS}

Berlant, L., y Warner, M. (2000). Sex in public. En L. Berlant (Ed.), Intimacy (pp. 311-330). Chicago: University of Chicago Press.

Bidaseca, K., y Vázquez, L. (Comps.) (2011). Feminismos y poscolonialidad. Descolonizando el feminismo desde y en América Latina. Buenos Aires: Godot.

Butler, J. (2001). El grito de Antígona. Barcelona: El Roure.

Castellano, A. M. (2004). La construcción de la planificación popular: diálogo de saberes. Espacio Abierto, 13(1), 75-96.

Castro-Gómez, S., y Grosfoguel, R. (2007): Prólogo. Giro decolonial, teoría crítica y pensamiento heterárquico. En El giro decolonial. Reflexiones para una diversidad epistémica más allá del capitalismo global (pp. 9-23). Bogotá: Siglo del Hombre, Editorial Universidad Javeriana.

Cuevas, P. (2013). Memoria colectiva: hacia un proyecto decolonial. En C. Walsh (Ed.), Pedagogías decoloniales. Prácticas insurgentes de resistir, (re)existir y (re)vivir (pp. 69-103). Quito: Abya Yala.

Curiel, O. (2014): Hacia la construcción de un feminismo descolonizado. En Y. Espinosa, D. Gómez y K. Ochoa (Eds.), Tejiendo de otro modo: feminismo, epistemología y apuestas descoloniales (pp. 325-334). Popayán: Universidad del Cauca.

Chrix, E. (2009). Los cuerpos y las mujeres kaqchikeles. Desacatos, 30, 149-160.

Espinosa, Y., Gómez, D., y Ochoa, K. (Eds.) (2014). Tejiendo de otro modo: feminismo, epistemología y apuestas descoloniales. Popayán: Universidad del Cauca.

Freire, P. (2009). Pedagogía de la esperanza. México: Siglo XXI.

Gargallo, F. (2012). Feminismos desde Abya Yala. Ideas y proposiciones de las mujeres de 607 pueblos en Nuestra América. Bogotá: Desde Abajo.

Gómez, D., Espinosa, Y., Lugones, M., y Ochoa, K. (2013). Reflexiones pedagógicas en torno al feminismo descolonial. Una conversa a cuatro voces. En C. Walsh (Ed.), Pedagogías decoloniales: prácticas insurgentes de resistir, (re)existir y (re)vivir (pp. 403-441). Quito: Abya Yala. 
Hernández, A. (2014). Algunos aprendizajes en el difícil reto de descolonizar el feminismo En M. Millán (Coord.), Más allá del feminismo. Caminos para andar (pp. 183-211). México: Red de Feminismos Descoloniales/Pez en el Árbol.

Lugones, M. (2008). Colonialidad y género. Tabula Rasa, 9, 73-101.

Martín, L. (2000). Phenomenology, post-structuralism and feminist theory on the concept of experience. En L. Fisher y L. Embree (Eds.), Feminist Phenomenology (pp. 39-56). Boston/Londres: Kluwer.

Mendoza, B. (2010). La epistemología del sur, la colonialidad del género y el feminismo latinoamericano. En Y. Espinosa (Coord.), Aproximaciones críticas a las prácticas teórico-políticas del feminismo latinoamericano (pp. 19-36). Vol. I. Buenos Aires: En la Frontera.

Quijano, A. (2000). Colonialidad del poder, eurocentrismo y América Latina. En E. Lander y S. Castro-Gómez (Comps.), La colonialidad del saber: eurocentrismo y ciencias sociales. Perspectivas latinoamericanas (pp. 201-246). Buenos Aires: Clacso.

Radstone, S., y Hodgkin, K. (2003). Introduction. Contested Pasts. En K. Hodgkin y S. Radstone (Eds.), Contested Pasts. The Politics of Memory (pp. 1-21). Londres: Routledge.

Rich, A. (1980). Compulsory heterosexuality and lesbian existence. Signs, 5(4), 631-660.

Rivera, C. (2008). Autoetnografía con otro. En La frontera más distante (pp. 29-55). México: Tusquets.

Santos, B. (2009). Una epistemología del sur. México: Siglo XXI.

Scott, J. (2001). Experiencia. La Ventana, 13, 42-73.

Steiner, G. (2009). Antígonas: una poética y filosofía de la lectura. Barcelona: Gedisa. 